\title{
Oxidative Stress Following Traumatic Brain Injury: Enhancement of Endogenous Antioxidant Defence Systems and the Promise of Improved Outcome
}

\author{
Eghwrudjakpor P O, MBBS, DMS, FICS Allison A B, MBBS, FRCS, FICS \\ Department of Surgery University of Port Harcourt Teaching Hospital, Port Harcourt Nigeria
}

\begin{abstract}
Background: Management of brain injury can pose enormous challenges to the health team. There are many studies aimed at discovering or developing pharmacotherapeutic agents targeted at improving outcome of head-injured patients. This paper reviews the role of oxidative stress in neuronal loss following traumatic brain injury and presents experimental and clinical evidence of the role of exogenous antioxidants as neuroprotectants.
\end{abstract}

Method: We reviewed published literature on reactive oxygen species and their role in experimental and clinical brain injuries in journals and the Internet using Yahoo and Google search engines.

Results: Traumatic brain injury causes massive production of reactive oxygen species with resultant oxidative stress. In experimental brain injury, exogenous antioxidants are useful in limiting oxidative damage. Results with clinical brain injury are however more varied.

Conclusion: Oxidative stress due to excessive generation of reactive oxygen species with consequent impairment of endogenous antioxidant defence mechanisms plays a significant role in the secondary events leading to neuronal death. Enhancement of the defence mechanisms through the use of exogenous antioxidants may be neuroprotective, especially if the agents can penetrate cell membranes, are able to cross the blood-brain barrier and if they are administered within the neuroprotective time window.

Keywords: Antioxidants; Oxidative stress; Outcome; Pathophysiology; Reactive oxygen species; Traumatic brain injury

Date Accepted for publication: 15th Dec 2009

Nig J Med 2010; 14-21

Copyright (2010 Nigerian Journal of Medicine

\section{Introduction}

Traumatic Brain Injury (TBI) is a worldwide problem $^{1}$, and its management can pose enormous challenges to the medical team as well as significantly stretch hospital resources (including manpower, facilities, etc). It is predominantly a "disease" of young persons and has assumed such immense proportions that the World Health Organisation (WHO) has placed it as a 21st century epidemic equivalent only to malaria and HIV/AIDS ${ }^{2}$. The last few decades have witnessed tremendous advances in virtually every aspect of TBI, but perhaps the area where this has been most remarkable is in the understanding of the pathophysiological processes attending the injury. Though many questions remain unresolved, research studies have shed much light on the accompanying events. It is now believed that even though the initial injury, which may be focal or diffuse, may produce neuronal damage or death, it also sets off a cascade of other events including the effects of hypoxia, release of endogenous excitatory amino acids (such as glutamate), production of pro-inflammatory substances as well as the generation of free radicals ${ }^{1,3}$.

Experimental studies have shown that one of the key participants in the events leading to secondary brain damage is oxidative stress (OS), which is believed to be the common pathway for diverse brain disorders ${ }^{4}$; and it is thought that defining its role in central nervous system injury could help with the development of novel, clinically applicable therapies ${ }^{5}$. Thus, several of the ongoing research efforts aimed at discovering measures targeted at improving the outcome of patients following $\mathrm{TBI}$ are the direct consequences of the recognition of the possible role of oxidative stress in its pathophysiology. 
This brief review deals with the sources and nature of reactive oxygen species, their role in traumatic brain injury and the endogenous antioxidant defence mechanisms. It also summarises new pharmacological strategies some of which are at various stages of clinical trial, and presents experimental and clinical evidence of the role of exogenous antioxidants as neuroprotectants in traumatic brain injury. The need for more clinical trials is highlighted.

\section{Free Radicals and Oxidative Stress}

Free radicals are highly reactive compounds which are mostly generated during cellular respiration and normal metabolism ${ }^{6}$. Their possession of unpaired electrons in their outer shell causes them to be more reactive than their corresponding nonradicals. This is because they act as electron acceptors, and essentially "steal" electrons from other molecules and thereby modify their chemical structures - an action which is referred to as oxidation?

Free radicals are liberated from a variety of sources, including inflammatory cells, dysfunctional mitochondria and excitotoxic mechanisms which are stimulated by increased glutamate and aspartate concentrations ${ }^{8}$. Superoxide radical is the most commonly occurring cellular free radical and it is produced when an oxygen molecule gains one electron from another compound ${ }^{6}$.

There is a vast amount of evidence implicating oxygen-derived free radicals as well as other highenergy oxidants as playing mediatory roles in diverse pathological conditions ${ }^{6,9-14}$. They have also been shown to be key contributors in the secondary events following brain injury ${ }^{7,15-17}$; and the formation of the oxygen radical, superoxide anion, is believed to be one of the final events of several metabolic pathways in the cascade which leads to delayed neuronal death after traumatic or ischaemic brain injury ${ }^{18}$. Cellular injury caused by reactive oxygen species (including free radicals, peroxides and oxygen ions), is believed to occur as a result of oxidation of polydesaturated fatty acids in lipids, oxidation of amino acids in proteins, damage of the DNA and inactivation of specific enzymes by oxidation of co-factors ${ }^{19}$.
Oxygen free radicals are produced continuously in tissues, and even though they are considered to be destructive agents, they can sometimes be useful. It is believed that they act as secondary messengers in intracellular signalling cascades which are responsible for the induction and maintenance of the oncogenic phenotype of cancer cells. They may also function as antitumourigenic species ${ }^{20}$.

Normally, a state of equilibrium exists between tissue oxidant and antioxidant activities ${ }^{21}$. This balance can, however, be upset as a result of excessive free radical generation, depletion of endogenous antioxidants or failure to repair oxidative injury induced by reactive oxygen species. The resultant condition is referred to as oxidative stress $(\mathrm{OS})^{11,22,23}$. Enhanced oxidative stress associated with increased production of free radicals has been implicated in the disruption of neuronal homeostasis induced by traumatic brain injury ${ }^{24-29}$.

Traumatic brain injury (TBI) leads to massive production of reactive oxygen species (ROS), which in turn mediate further damage via various cellular molecular pathways, including damage to cellular components like lipids, proteins and nucleic acids $6,{ }^{30-33}$ with neuronal death occurring as a result of impairment of cellular calcium homeostasis, tissue acidosis, and oxidative stress $^{34}$. OS is also thought to, at least in part, initiate or influence autophagy - a process whereby cellular components are digested by enzymes within the same cell ${ }^{35}$. Experimental data indicate that the destructive oxidative events following TBI reach their peak within the first 24 hours of injury, and that the brain damage that occurs as a result of the impact can be the cause of death or irreversible permanent disabilities in affected patients ${ }^{36}$. The degree of oxidative injury in clinical TBI is, however, not yet completely understood ${ }^{5}$.

\section{Endogenous Antioxidant Defence Mechanisms}

Antioxidants are compound whose actions include: inhibition of the formation of reactive oxygen species and binding of metal ions needed 
for catalysis of their generation, and scavenging of reactive oxygen species or their precursors. They inhibit other oxidation reactions by being oxidized themselves. Endogenous antioxidant scavenger mechanisms help to defend cells against oxidative injury $^{37-39}$. Two major groups of these compounds are recognised: antioxidant enzymes (such as superoxide dismutase, catalase and glutathione peroxidise), and low molecular weight antioxidants (LMWA) The latter group contains directly acting agents (such as ascorbic acid, lipoic acid, uric acid, $\alpha$-Tocopherol, ubiquinol and carotenoids) and indirectly acting antioxidants (e.g. chelating agents) ${ }^{5,6}$.

The high rate of oxidative metabolism in the normal brain and its elevated levels of polyunsaturated lipids (which are the target of lipid peroxidation) render it particularly vulnerable to oxidative stress $^{19,40,41}$. Oxidative damage is, however, prevented by the actions of endogenous antioxidants. Free radicals, especially superoxide and some non-radicals, (e.g. hydrogen peroxide), can be generated in such large quantities that the endogenous protective enzyme systems are overwhelmed $^{42}$. When there is brain trauma, the regulatory mechanisms are also progressively compromised and they may either be eliminated altogether or even be converted to become prooxidant $^{5,6,33,43}$. Environmental as well as genetic factors are thought to play some role in the reduction in the endogenous antioxidant defence system and thereby contribute to the evolution of oxidative stress ${ }^{6}$. Experimental studies have shown that enhancing this endogenous antioxidant defence mechanism may be neuroprotective during injury.

\section{Exogenous Antioxidants}

There are several research studies on the use of exogenous antioxidants in TBI. Most of these are hinged on the belief that the free radicals (which are by-products of increased neurotransmitter activity), are the agents actually responsible for neuronal death ${ }^{40}$. A number of therapeutic trials based the ability of antioxidants to scavenge free radicals have been attempted in both experimental $\left.\right|^{44,45}$ and clinical TBI ${ }^{46}$.
It is thought that antioxidants that would effectively cross the blood-brain barrier and penetrate into the damaged tissue may help to maintain the redox status of the neurons, decrease ROS-associated neuronal damage and thus reduce neurological impairment and disability ${ }^{47}$.

Furthermore, to be effective, such antioxidant should be given within the neuroprotective "time window", which is the time interval between the trauma event and irreversible neuronal loss. When given during this period, they may be expected to significantly reduce or prevent cerebral damage ${ }^{6,48}$. However, majority of the currently available antioxidants are not able to cross the blood-brain barrier from the systemic circulation, thereby limiting their efficacy as neuroprotectants.

Animal studies have shown that antioxidant administration interrupts the sequence of brain injury responses ${ }^{15,18,49}$. Results with clinical TBI have, however, been more varied ${ }^{6}$. In some studies involving TBI patients, the exogenous antioxidants were reported to have no beneficial effects. Young et al carried out a randomized, parallel, placebo-controlled, third-party-blind, multicenter trial of pegorgotein (a scavenger of oxygen-derived free radicals), with the aim of evaluating its effects on neurologic outcome of patients with severe closed head injury. They reported that even though pegorgotein was well tolerated at 3 months after injury, there was no significant statistical difference in neurologic outcome between the pegorgotein and the placebo-treated groups. However, there was no increase in the mortality or disability states among the patients given pegorgotein ${ }^{50}$.

Other studies have shown that the neutralisation of ROS by endogenous or exogenous antioxidants has a protective effect on brain tissue. The study by Shohami et al demonstrates that the brain responds to ROS by increasing low molecular weight antioxidants and that among head-injured patients, the degree of the response correlates well with clinical recovery: the greater the response, the more favourable the outcome $e^{15}$. 
Similarly, in a randomised controlled Phase II trial to evaluate the safety and efficacy of polyethylene glycol-conjugated superoxide dismutase (PEGSOD) in severely head-injured patients, Muizelaar et al reported significantly improved outcome in the groups of patients treated with PEG-SOD as compared with their placebo-treated groups ${ }^{18}$. It thus appears from these reports that there might some promise in the use of exogenous antioxidants in situations where the natural defence mechanisms are compromised.

Uric acid (UA), which is one of the most abundant aqueous antioxidants in humans is thought to account for as much as two-thirds of all free radical scavenging capacity in plasma (being found to be particularly effective in quenching hydroxyl, superoxide and peroxynitrite radicals) ${ }^{51}$. Experimental data have shown that local uric acid concentrations are significantly increased in acute traumatic brain injury $y^{52}$; and that early elevation of $\mathrm{UA}$, during or shortly after TBI and other cerebral disorders mediated by free radicals, could confer significant protection against the occurrence of neurological deficits ${ }^{53}$.

Ascorbic acid is known to be a very effective free radical scavenger. It is not synthesised in humans and as such, it must be obtained from dietary sources. Even though its exact functions are not known, it is believed that ascorbic acid can neutralise reactive oxygen species such as hydrogen peroxide which are produced during $\mathrm{TB}^{54}$. In addition to its direct antioxidant effects, ascorbic acid is also a substrate for the antioxidant enzyme ascorbate peroxidise.

Melatonin is also a very potent antioxidant and direct free radical scavenger that is particularly efficacious because of its ability to penetrate cell membranes as well as cross the blood-brain barrier. It protects against oxidative damage at the level of cells, tissues, organs and organisms. Its antioxidative mechanisms seem different from those of the classical antioxidants in that whereas the latter undergo redox cycling and thus have the potential to promote oxidation as well as prevent it, melatonin does not and as such, it does not promote oxidation.
Melatonin has been referred to as a terminal (or suicidal) antioxidant because once oxidized, it cannot be reduced to its former state because it forms several stable end-products upon reacting with free radicals $\mathrm{s}^{43,55-57}$.

Another group of antioxidants that has received tremendous attention during the last few years are the cannabinoids. These include compounds which have similar structure with the psychoactive components in cannabis, as well as agents which activate the cannabinoid receptor system in the body. Researchers have shown that the cannabinoids are effective neuroprotectants in experimental animals. Some of them, such as the synthetic cannabinoid, dexanabinol (HU211), are at various stages of clinical trials. The results have so far been promising. In a prospective, randomised, double-blind, placebocontrolled, multicenter study including six Israeli neurosurgical intensive care units, dexanabinol was shown to be safe and well tolerated in severely headed-injured patients. The treated patients achieved significantly better intracranial pressure/cerebral perfusion pressure control. The authors also observed a trend towards faster and better neurologic outcome. While confirming the strong cerebroprotective effect of dexanabinol, the study by Shohami et al also showed a therapeutic window of about 4 hours ${ }^{3,58}$.

Dexanabinol is a promising drug which does not produce psychotrophic or other adverse side effects associated with some of the earlier drugs of its type ${ }^{59}$. Though the neuroprotective effect of the cannabinoids is thought to be due to their strong antioxidant property, some researchers consider that this attribute alone is unlikely to account for all of the protection. It is thought that an additional mechanism whereby they provide their protective effect is by the inhibition of the glutamate system in the brain thereby dampening neural activity with consequent reduction of excitotoxicity. 


\section{Conclusion}

Traumatic brain injury remains a significant problem worldwide. Oxidative stress plays a significant role in neuronal death following injury due to the progressive compromise of endogenous antioxidant defence systems. The neutralisation of reactive oxygen species by endogenous or exogenous antioxidants has a protective effect on the brain.

\section{References}

1. Guha A. Management of traumatic brain injury: some current evidence and applications. Postgraduate Medical Journal 2004; 80: 650-653.

2. Chua KSG, Ng Y, Yap SGM, Bok C. A Brief Review of Traumatic Brain Injury Rehabilitation. Ann Acad Med Singapore 2007; 36: 31-42.

3. Shohami E, Gallily R, Mechoulam R, Bass R, Ben-Hur T. Cytokine production in the brain following closed head injury: dexanabinol (HU211) is a novel TNF-alpha inhibitor and an effective neuroprotectant. J Neuroimmunol 1997; 72(2): 169-177.

4. de Almeida LM, Leite MC, Thomazi AP, Battu C, Nardin P, Tortorelli LS, Zanotto C, Posser T, Wofchuk ST, Leal RB, Gonçalves CA, Gottfried C. Resveratrol protects against oxidative injury induced by $\mathrm{H} 2 \mathrm{O} 2$ in acute hippocampal slice preparations from Wistar rats. Arch Biochem Biophys 2008; 480(1): 27-32.

5. Bayir $H$, Kagan VE, Tyurina YY, Tyurin V, Ruppel RA, Adelson PD, Graham SH, Janesko K, Clark RS, Kochanek PM. Assessment of Antioxidant Reserves and Oxidative Stress in Cerebrospinal Fluid after Severe Traumatic Brain Injury in Infants and Children. Pediatr Res 2002; 51(5): 571-578.

6. Gilgun-Sherki Y, Rosenbaum Z, Melamed E, Offen D. Antioxidant Therapy in Acute Central Nervous System Injury: Current State. Pharmacological Reviews 2002; 54(2): 271284.

7. Marklund N, Sihver S, Långström B, Bergström M, Hillered L. Effect of traumatic brain injury and nitrone radical scavengers on relative changes in regional cerebral blood flow and glucose uptake in rats. J Neurotrauma 2002; 19(10): 1139-1153.
Consequently, the discovery and development of antioxidant agents is one of the most promising approaches in the search for more effective treatment of TBI. Several potentially useful agents have been identified, and even though the effect of many of them in clinical TBI is still controversial, some have shown some promise. More clinical trials are however needed to resolve some of the ongoing controversy.

8. Sun AY, Chen Y. Oxidative stress and neurodegenerative disorders. J Biomed Sci 1998; 5: 401-414

9. Watanabe T, Tanaka M, Watanabe K, Takamatsu Y, Tobe A. Research and development of the free radical scavenger edaravone as a neuroprotectant. Yakugaku Zasshi 2004; 124(3): 99-111.

10. Love S. Oxidative stress in brain ischaemia. Brain Pathol 1999; 9: 119-131.

11. Ma A, Qi S, Chen H. Antioxidant therapy for prevention of inflammation, ischemic reperfusion injuries and allograft rejection. Cardiovasc Hematol Agents Med Chem 2008; 6(1): 20-43.

12. Tanaka M. Pharmacological and clinical profile of the free radical scavenger edaravone as a neuroprotective agent. Nippon Yakurigaku Zasshi 2002; 119(5): 301308.

13. Egashira T, Takayama F, Yamanaka Y. Detection and characterization of free radicals, radical scavenging activity, and lipid peroxides in cerebral ischemia-reperfusion injury by electron spin resonance and chemiluminescence high-performance liquid chromatography. Nihon Shinkei Seishin Yakurigaku Zasshi 1997; 17(4): 153-158.

14. Halliwell B, Gutteridge GMC, Corss CE. Free radicals and antioxidants and human disease: where we are now? J Lab Clin Invest 1992; 119: 589-620.

15. Shohami E, Beit-Yannai E, Horowitz M, Kohen R. Oxidative stress in closed-head injury: Brain antioxidant capacity as an indicator of functional outcome. J Cereb Blood Flow Metab 1997; 17(10): 1007-1019. 
16. Nayak CD, Nayak DM, Raja A, Rao A. Timerelative changes in the erythrocyte antioxidant enzyme activities and their relationship with Glasgow Coma Scale scores in severe head injury patients in the 21-day posttraumatic study period. Indian J Med Sci 2007; 61: 381389.

17. Moor E, Kohen R, Reiter RJ, Shohami E. Closed head injury increases extracellular levels of antioxidants in rat hippocampus in vivo: an adaptive mechanism? Neurosci-Lett 2001; 316(3): 169-172.

18. Muizelaar JP, Marmarou A, Young HF, Choi SC, Wolf A, Schneider RL, Kontos HA. Improving the outcome of severe head injury with the oxygen radical scavenger polyethylene glycolconjugated superoxide dismutase: a phase II trial. J Neurosurg 1993; 78(3): 375-382.

19. Warner DS, Sheng H, Batini-Haberle I. Oxidants, antioxidants and the ischemic brain. Journal of Experimental Biology 1004; 207: 3221-3231.

20. Valko M, Leibfritz D, Moncol J, Cronin MT, Mazur M, Telser J. Free radicals and antioxidants in normal physiological functions and human disease. Int J Biochem Cell Biol 2007; 39(1): 44-84.

21. Frei $B$, Stocker $R$, Ames BN. Antioxidant defences and lipid peroxidation in human blood plasma. Proc Natl Acad Sci USA 1988; 85: 9748-9752.

22. Ebadi M, Srinivasan SK and Baxi MD. Oxidative stress and antioxidant theory in Parkinson's disease. Prog Neurobiol 1996; 48: 1-19.

23. Maritim AC, Sanders RA, Watkins JB. Diabetes, oxidative stress, and antioxidants: a review. J Biochem Mol Toxicol 2003; 17: 24-38.

24. Facchinetti F, Dawson VL and Dawson TM. Free radicals as mediators of neuronal injury. Cell Mol Neurobiol 1998; 18: 667-682.

25. Hall ED, Yonkers PA, McCall JM, Braughler JM. Effects of the 21-aminosteroid U74006F on experimental head injury in mice. J Neurosurg 1988; 68: 456-461.

26. Tyurin VA, Tyurina YY, Borisenko GG, Sokolova TV, Ritov VB, Quinn PJ, Rose M, Kochanek P, Graham SH, Kagan VE. Oxidative stress following TBI in rats: quantitation of biomarkers and detection of free radical intermediates. J Neurochem 2000; 75: 2178-2179.
27. Wada K, Alonso OF, Busto R, Panetta J, Clemens JA, Ginsberg MD, Dietrich WD. Early treatment with a novel inhibitor of lipid peroxidation (ly341122) improves histopathological outcome after moderate fluid percussion brain injury in rats. Neurosurgery 1999; 45: 601-608.

28. Marklund $N$, Sihver $S$, Långström $B$, Bergström M, Hillered L. Effect of traumatic brain injury and nitrone radical scavengers on relative changes in regional cerebral blood flow and glucose uptake in rats. J Neurotrauma 2002; 19(10): 1139-1153.

29. Varma S, Janesko KL, Wisniewski SR, Bayir H, Adelson PD, Thomas NJ, Kochanek PM. F2isoprostane and neuron-specific enolase in cerebrospinal fluid after severe traumatic brain injury in infants and children. J Neurotrauma 2003; 20(8): 781-786.

30. Koç RK, Kurtsoya, Pasaoglu H, Karaküçük EI, Öktem1S, Meral M. Lipid peroxidation and oedema in experimental brain injury: comparison of treatment with methylprednisolone, tirilazad mesylate and vitamin E. Res Exp Med 1999; 199(1): 21-28.

31. DeKosky ST, Abrahamson EE, Taffe KM, Dixon CE, Kochanek PM, Ikonomovic MD. Effects of post-injury hypothermia and nerve growth factor infusion on antioxidant enzyme activity in the rat: implications for clinical therapies. Journal of Neurochemistry 2004; 90(4); 998-1004.

32. Leinenweber SB, Sheng $H$, Lynch JR, Wang $H$, Batinić-Haberle I, Laskowitz DT, Crapo JD, Pearlstein RD, Warner DS. Effects of a manganese (III) porphyrin catalytic antioxidant in a mouse closed head injury model. European Journal of Pharmacology 2006; 531: 126-132.

33. Beni SM, Kohen R, Reiter RJ, Tan D, Shohami E. Melatonin-induced neuroprotection after closed head injury is associated with increased brain antioxidants and attenuated late-phase activation of NF-B and AP-1. The FASEB Journal 2004; 18: 149-151.

34. Kochanek PM, Clark RSB, Ruppel RA, Adelson $P D$, Bell MJ, Whalen MJ, Robertson CL, Satchell MA, Seidberg NA, Marion DW, Jenkins LW. Biochemical, cellular and 
35. Molecular mechanisms in the evolution of secondary damage after severe TBI in infants and children: lessons learned from the bedside. Pediatr Crit Care Med 2000; 1: 4-19.

36. Lai Y, Hickey RW, Chen Y, Bayir H, Sullivan ML, Chu CT, Kochanek PM, Dixon CE, Jenkins LW, Graham SH, Watkins SC, Clark RS. Autophagy is increased after traumatic brain injury in mice and is partially inhibited by the antioxidant gamma-glutamylcysteinyl ethyl ester. J Cereb Blood Flow Metab 2008; 28(3): 540-550.

37. Nayak C. Relationship between neurological outcome and early oxidative changes in erythrocytes in head injury patients. Clinical Chemistry and Laboratory Medicine 2007; 45(5); 629-633.

38. Evans $\mathrm{PH}$. Free radicals in brain metabolism and pathology. Br Med Bull 1993; 49: 577-587. Chan PH. Role of oxidants in ischaemic brain damage. Stroke 1996; 27: 1124-1129.

39. Shrinivas K, Vijaya Bhaskar M, Aruna Kumari M, Nagaraj K, Reddy KK. Antioxidants, lipid peroxidation and lipoproteins in primary hypertension. Indian Heart J 2000; 52: 285288.

40. Carney JM, Floyd RA. Protection against oxidative damage to CNS by alpha-phenyltert-butyl nitrone (PBN) and other spintrapping agents: a novel series of nonlipid free radical scavengers. J Mol Neurosci 1991; 3(1): 47-57.

41. Ames BN, Shigenega MT, Hagen M. Oxidants, antioxidants and the degenerative diseases of aging. Proc Natl Acad Sci USA 1993; 90: 79157922.

42. Slemmer JE, Shacka JJ, Sweeney MI, Weber JT. Antioxidants and free radical scavengers for the treatment of stroke, traumatic brain injury and aging. Curr Med Chem 2008; 15(4): 404414.

43. Ozdemir D, Uysal N, Gonenc S, Acikgoz O, Sonmez A, Topcu A, Ozdemir N, Duman M, Semin I, Ozkan H. Effect of Melatonin on Brain Oxidative Damage Induced by Traumatic Brain Injury in Immature Rats. Physiol Res 2005; 54 : 631-637.
44. Inci S, Ozcan O, Kilinic K. Time-level relationship for lipid peroxidation and the protective effect of $\alpha$-tocopherol in experimental mild and severe brain injury. Neurosurgery 1998; 43: 330-335.

45. Sen S, Goldman H, Morehead M, Murphy S, Phillis JW. Oxypurinol inhibits free radical release from the cerebral cortex of closed head injured rats. Neurosci Lett 1993; 162: 117-120.

46. Wahlgren NG. A review of earlier clinical studies on neuroprotective agents and current approaches.In: Green AR, Cross AJ (eds) Neuroprotective Agents and Cerebral Ischaemia. Academic Press, San Diego, 1997; pp 337-363.

47. Hall ED, Andrus PK, Smith SL, Fleck TJ, Scherch HM, Lutzke BS, Sawada GA, Althaus JS, Vonvoigtlander PF, Padbury GE, Larson PG, Palmer JR, Bundy GL. Pyrrolopyrimidines: novel brain-penetrating antioxidants with neuroprotective activity in brain injury and ischaemia models. J Pharmacol Exp Ther 1997; 281(2): 895-904.

48. Kaplan B, Brint S, Tanabe J, Jacewicz M, Wang $\mathrm{XJ}$ and Pulsinelli W. Temporal thresholds for neocortical infarction in rats subjected to reversible focal cerebral ischaemia. Stroke 1991; 22: 1032-1039.

49. Hamm RJ, Temple MD, Pike BR, Ellis EF. The effect of postinjury administration of polyethylene glycol-conjugated superoxide dismutase (pegorgotein, Dismutec) or lidocaine on behavioural function following fluid-percussion brain injury in rats. J Neurotrauma 1996; 13(6): 325-332.

50. Young B, Runge JW, Waxman KS, Harrington T, Wilberger J, Muizelaar JP, Boddy A, Kupiec JW. Effects of pegorgotein on neurologic outcome of patients with severe head injury. A multicenter, randomized controlled trial. JAMA 1996; 276(7): 538-543.

51. Squadrito $G L$, Cueto $R$, Splenser $A E$, Valavanidis A, Zhang $H$, Uppu RM, Pryor WA. Reaction of uric acid with peroxynitrite and implications for the mechanism of neuroprotection by uric acid. Arch Biochem Biophys 2000; 376: 333-337 
52.Tayag EC, Nair SN, Wahhab $S$, Katsetos CD, Lighthall JW, Lehmann JC. Cerebral uric acid increases following experimental traumatic brain injury in rat. Brain Res 1996; 733: 287-291.

53. Waring WS. Uric acid: an important antioxidant in acute ischaemic stroke. Q J Med 2002; 95: 691-693.

54. Frei B, England L, Ames BN. Ascorbate is an outstanding antioxidant in human blood plasma. Proc Natl Acad Sci USA 1989; 86: 63776381.

55.Reiter RJ, Korkmaz A. Clinical aspects of melatonin. Saudi Med J 2008; 29(11): 15371547.

56.Tan DX, Manchester LC, Reiter RJ, Qi WB, Karbownik M, Calvo JR.
Significance of melatonin in antioxidative defence system: reactions and products. Biol Signals Recept 2000; 9: 137-159.

Reiter RJ, Tan DX, Manchester LC, Tamura H.

57. Melatonin defeats neurally-derived free radicals and reduces the associated neuromorphological and neurobehavioral damage. J Physiol Pharmacol 2007; 58: 5-22.

58. Shohami E, Novikov M, Bass R. Long-term effect of HU-211, a novel non-competitive NMDA antagonist, on motor and memory functions after closed head injury in the rat. Brain Res 1995; 674(1): 55-62.

59. Darlington CL. Dexanabinol: a novel cannabinoid with neuroprotective properties. Drugs 2003; 6(10): 976-979. 